\title{
Sensoriamento remoto de alta resolução temporal para uma observação dinâmica dos ambientes tropicais
}

\author{
High temporal resolution remote sensing for \\ dynamic observation of tropical environment \\ Teledetección de alta resolución temporal para \\ una observación dinámica de ambientes tropicales
}

Laurent Polidori ${ }^{1}$

\section{Resumo}

POLIDORI, L. Sensoriamento remoto de alta resolução temporal para uma observação dinâmica dos ambientes tropicais. Rev. C\&Trópico, v. 44, n. 1, p. 235-255, 2020. DOI: https://doi. org/10.33148/cetropicov44n1(2020)art11

Este artigo propõe uma discussão sobre a noção de resolução temporal e apresenta vantagens e limitações dos sistemas de observação de alta resolução temporal. Estes sistemas permitem acompanhar fenômenos ambientais dinâmicos assim como melhorar a qualidade da interpretação das imagens em geral. Para ilustrar as possibilidades oferecidas pelos sistemas espaciais de alta resolução temporal, três exemplos são apresentados em áreas tropicais, onde fenômenos temporais, tanto naturais quanto antrópicos, são estudados a partir de séries de imagens com alta resolução temporal.

Palavras-chave: Sensoriamento remoto. Séries temporais. Ambientes tropicais.

\section{Abstract}

POLIDORI, L. High temporal resolution remote sensing for dynamic observation of tropical environment. Rev. CઐTrópico, v. 44, n. 1, p. 235-255, 2020. DOI: https://doi.org/10.33148/cetropicov44n1(2020)art11

This article proposes a discussion on the concept of temporal resolution, and presents advantages and limitations of high temporal resolution observation systems. Such systems allow to follow dynamic environmental phenomena and to improve the quality of image interpretation in general. In order to illustrate the possibilities offered by high temporal resolution space systems, three examples are presented in tropical areas where temporal phenomena, both natural and anthropic, are studied based on high temporal resolution image series.

Keywords: Remote sensing. temporal series. tropical environments.

\footnotetext{
Pesquisador titular, diretor do Centro de Estudos Espaciais da Biosfera CESBIO, Université de Toulouse. E-mail:
} laurent.polidori@cesbio.cnes.fr. Orcid: https://orcid.org/0000-0001-6220-9561 


\section{Resumen}

POLIDORI, L. Teledetección de alta resolución temporal para una observación dinámica de ambientes tropicales. Rev. CßTrópico, v. 44, n. 1, p. 235-255, 2020. DOI: https://doi.org/10.33148/ cetropicov44n1(2020)art11

Este artículo propone una discusión sobre la noción de resolución temporal, y presenta ventajas y limitaciones de los sistemas de observación de alta resolución temporal. Estos sistemas permiten monitorear fenómenos ambientales dinámicos, así como mejorar la calidad de la interpretación de las imágenes en general. Para ilustrar las posibilidades que ofrecen los sistemas espaciales con alta resolución temporal, se presentan tres ejemplos en áreas tropicales, donde se estudian los fenómenos temporales, tanto naturales como antrópicos, a partir de series de imágenes con alta resolución temporal.

Palabras clave: Teledetección. Series de tiempo. Ambientes tropicales.

Data de submissão: $13 / 01 / 2020$

Data de aceite: $28 / 04 / 2020$

\section{Introdução}

Com o número e a variedade cada vez maiores de sistemas de observação da Terra, as possibilidades de atualização da informação geográfica têm aumentado muito nas últimas décadas, e alguns sistemas são até desenhados para providenciar séries temporais de imagens com uma frequência determinada, tornando possível a implementação de programas de monitoramento do meio ambiente em áreas onde acontecem mudanças. Porém, o desenvolvimento de sistemas de alta resolução temporal, além de dificuldades técnicas de transmissão e armazenamento dos dados, tem produzido um novo paradigma, no qual o usuário não precisa mais olhar cada imagem individual, mas necessita implementar algoritmos automatizados.

No caso das imagens óticas, era comum ter acesso cada ano a duas ou três imagens viáveis (com uma cobertura nebulosa razoável), e os sistemas recentes de alta resolução temporal como Sentinel-2 têm aumentado a probabilidade de observar uma área determinada com poucas nuvens. No caso das imagens de radar, que são quase insensíveis à presença de nuvens, o benefício da alta resolução temporal é mais importante ainda. O sistema Sentinel-1 oferece, por exemplo, mais de trinta imagens em qualquer região do mundo, em algumas, mais de sessenta, permitindo um monitoramento quase contínuo do meio ambiente, principalmente nas zonas tropicais, em que as mudanças podem ser espetaculares, em pouco tempo, e nas quais as condições meteorológicas limitam muito as possibilidades de monitoramento com sensores óticos.

Neste artigo, são discutidas as vantagens e limitações da alta resolução temporal são discutidas. Após um sobrevoo geral dos diferentes tipos de mudança 
do meio ambiente, mostramos que eles podem ser detectados por sistemas de sensoriamento remoto, segundo diferentes critérios relacionados com as características geométricas, radiométricas ou interferométricas da superfície, permitindo uma variedade de possibilidades de monitoramento por satélite. Ao longo das últimas décadas, a evolução do desempenho dos sistemas espaciais de observação é comentada em termos de resolução espacial, espectral e temporal. No caso da resolução temporal, são apresentadas as possibilidades técnicas de melhoramento, assim como as contrapartidas positivas do custo tecnológico, tanto em termos de melhoramento da qualidade das imagens, quanto de possibilidades aumentadas de monitoramento dinâmico do meio ambiente. Finalmente, apresentamos três exemplos de trabalhos publicados sobre diferentes aplicações de séries temporais para o monitoramento da superfície terrestre em áreas tropicais. Os fenômenos ambientais estudados são tanto naturais (transporte de sedimentos no litoral da Guiana francesa) quanto antrópicos (agricultura no Vietnam, desmatamento da Amazônia).

\section{Monitoramento dinâmico do meio ambiente}

\subsection{Variedade dos fenômenos dinâmicos}

Mudanças acontecem na superfície da terra em todas as escalas espaciais e temporais, e têm uma grande variedade de causas, às quais se dividem em duas categorias: antrópicas (desmatamento, urbanização, construção de obras, exploração de recursos), gravitárias (deslizamentos, queda de pedras, erosão), geofísicas internas (fenômenos sísmicos, tectônicos, vulcânicos) e, principalmente, hidrológicas (inundações, erosão costeira).

Tais causas podem ter diferentes tipos de evolução através do tempo, como, por exemplo, uma evolução contínua, cíclica ou catastrófica (Figura1) ou uma combinação delas.

Figura 1: Diferentes tipos de evolução de uma variável ambiental com relação ao tempo. evolução contínua evolução cíclica evolução catastrófica

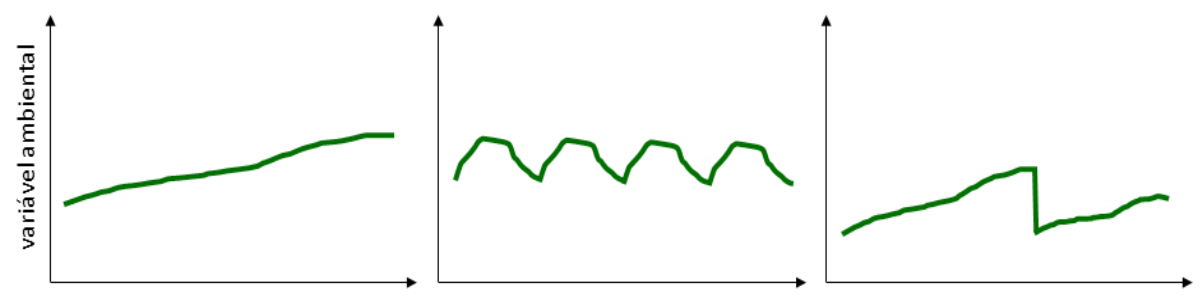

Fonte : Elaborado pelo autor. 
O tipo de evolução temporal influencia a possibilidade de modelar um fenômeno de mudança ambiental para prever estados futuros. A partir de um conhecimento $a$ priori do fenômeno e de dados de monitoramento, todo fenômeno pode ser antecipado até certo ponto, com uma parte inevitável de imprevisibilidade.

Uma mudança que acontece entre duas datas pode ter vários comportamentos que definem critérios para sua detecção e caracterização por meio do sensoriamento remoto. Os aspectos mais considerados nos estudos de sensoriamento remoto estão relacionados com os comportamentos radiométricos, geométricos e interferométricos.

- mudança radiométrica: acontece quando uma mudança ambiental transforma a cor da superfície (solo, água, vegetação) ao longo do tempo, devido à evolução das características da superfície (tipo de solo ou de vegetação, propriedades químicas e biológicas, temperatura, rugosidade, umidade, presença de poluição) ;

- mudança geométrica: acontece quando uma mudança ambiental gera uma reorganização espacial da matéria na escala do pixel. Pode ser uma mudança de localização ou deslocamento (por exemplo: um banco de areia ou de lama é transportado pelas correntes ao longo da costa), uma mudança de topologia (exemplo: um meandro fica isolado ou uma península vira ilha depois de uma fase de erosão), uma mudança de morfologia (um objeto muda de forma, a exemplo de uma parcela agrícola ou uma margem fluvial ou litoral). A Figura 2 ilustra essas diferentes configurações geométricas no caso $2 \mathrm{D}$, ou seja, numa superfície horizontal, mas os mesmos fenômenos podem ter uma componente vertical que exige uma observação em 3D.

Figura 2: Possíveis comportamentos geométricos de uma mudaça ambiental.

localização

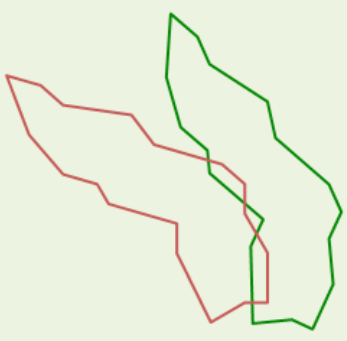

topologia

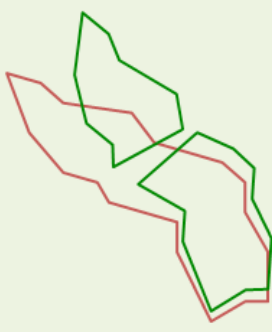

morfologia

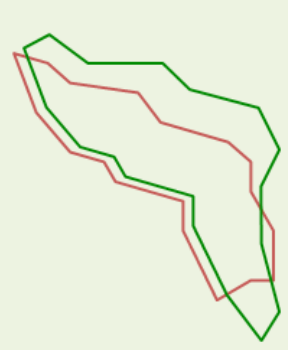

Fonte: Elaborado pelo autor.

- mudança interferométrica: no caso de observações por radar orbital, é preciso mencionar outro comportamento relacionado com a reorganização espacial da matéria na escala do comprimento de onda de um radar 
(deslocamento médio de ordem centimétrica). Pode se tratar de deslocamento coerente (toda a matéria se desloca com o mesmo movimento como no caso de uma subsidência) ou incoerente (redistribuição aleatória da matéria devida à instabilidade da superfície e favorecida pela presença de vegetação ou de água que gera agitação).

\subsection{Abordagens para o monitoramento por sensoriamento remoto}

A detecção e caracterização de uma mudança da superfície terrestre a partir de imagens tomadas por avião ou satélite pode ser feita de duas maneiras, levando à definição de duas abordagens a depender da disponibilidade de imagens durante o período estudado:

procurar testemunhos do passado em imagens do presente: isso supõe que os traços não tenham desaparecido totalmente e que existem sensores com a sensibilidade suficiente para revelá-los. A figura 3 mostra dois exemplos de feições antigas (uma antrópica e a outra natural) que ainda aparecem em imagens de sensoriamento remoto.

Figura 3: Observação de testemunhos do passado em imagens recentes.

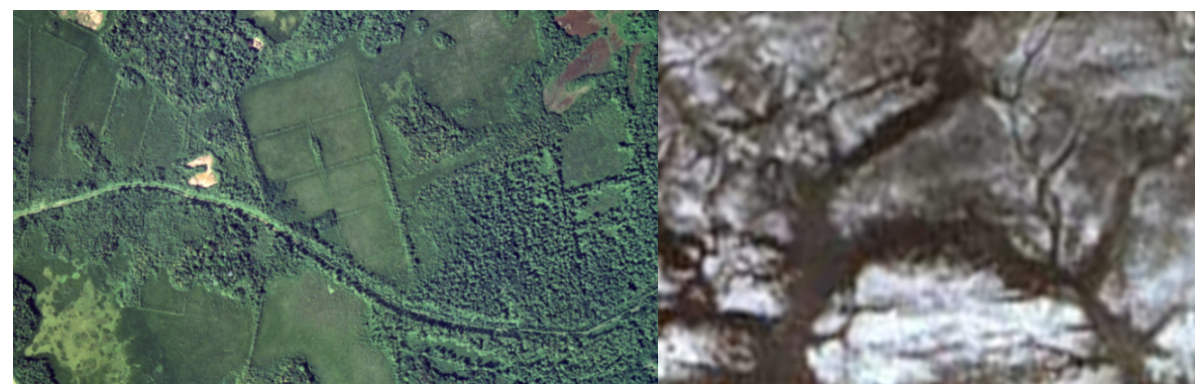

Fonte: IGN, 2018; NASA, 2018.

À esquerda, um polder que existiu numa fazenda do século 18 na Guiana francesa, aparecendo ainda numa fotografia aérea.

A direita, uma antiga rede hidrográfica no deserto do Saara, recoberta por uma camada de areia mas visível numa imagem de radar de grande comprimento de onda.

- comparar imagens tomadas em datas diferentes: neste caso a diferença entre as imagens pode indicar uma transformação. Essa abordagem depende da disponibilidade de imagens de acervo, que varia entre os diferentes países do mundo. Os maiores acervos aparecem depois da segunda guerra mundial (1945) para fotografias aéreas e depois do lançamento do primeiro Landsat (1972), para imagens de satélite. A Figura 4 mostra como fotografias aéreas podem revelar mudanças acontecidas nos últimos sessenta anos. 
Figura 4: Comparação de fotografias aéreas das décadas 1950 e 2010.

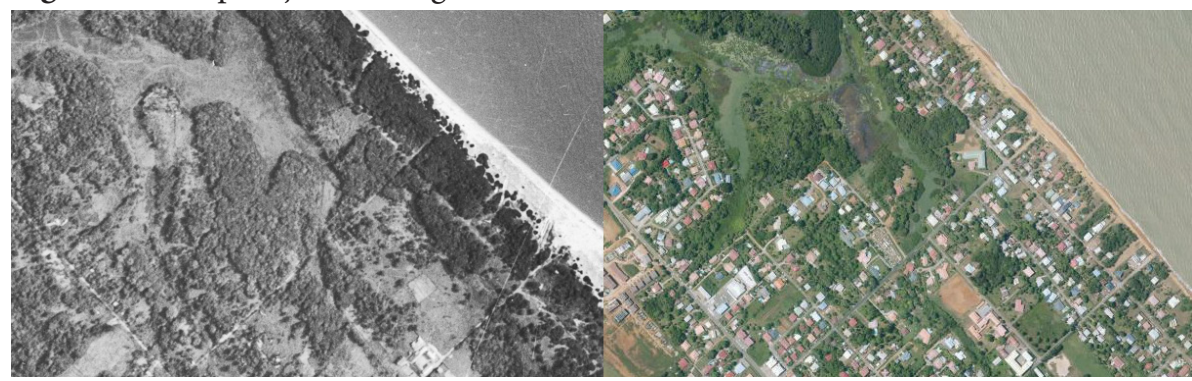

Fonte: IGN, 2018.

A comparação revela mudanças na região de Cayenne (Guiana francesa): urbanização, erosão da praia, evolução da hidrografia e da cobertura vegetal numa zona úmida.

A possibilidade de estudar a evolução do meio ambiente com essa segunda abordagem, stá relacionada com uma característica importante dos sistemas de observação: a resolução temporal.

\section{Promessas e limitações da alta resolução temporal}

A resolução temporal faz parte de três características essenciais dos sistemas de sensoriamento remoto que, no caso de sistemas espaciais, são definidos desde a fase de concepção: as resoluções espacial, espectral e temporal. A resolução espacial é relacionada com o tamanho do pixel e com a nitidez da imagem, que determinam a possibilidade de discriminar dois objetos pontuais próximos. A resolução espectral, favorecida por bandas espectrais estreitas e numerosas, se refere à possibilidade de caracterizar os objetos pela sua assinatura espectral (variação da reflectância em função do comprimento de onda). A resolução temporal, que consideramos neste artigo, se refere ao intervalo de tempo que é preciso esperar entre duas observações consecutivas da mesma área, seja o sistema programado para aquisições sistemáticas ou sob demanda.

\subsection{Evolução histórica das resoluções espacial, espectral e temporal}

A observação da Terra por satélite remonta há mais de meio século desde a aquisição da primeira imagem “Tiros” em 1960. A evolução mais dramática das ferramentas e dados de sensoriamento remoto durante esse período é a resolução espacial, que, originalmente, permite apenas localizar os continentes e acompanhar as grandes massas atmosféricas, enquanto as imagens de satélite da década de 2010, comparáveis às obtidas por aquisições aéreas, destacam objetos em escala humana, como veículos ou mobiliário urbano (Figura 5). 
Figura 5: Há meio seculo de distância, imagens Tiros (1960, esquerda) e Pleiades (2012, direita).
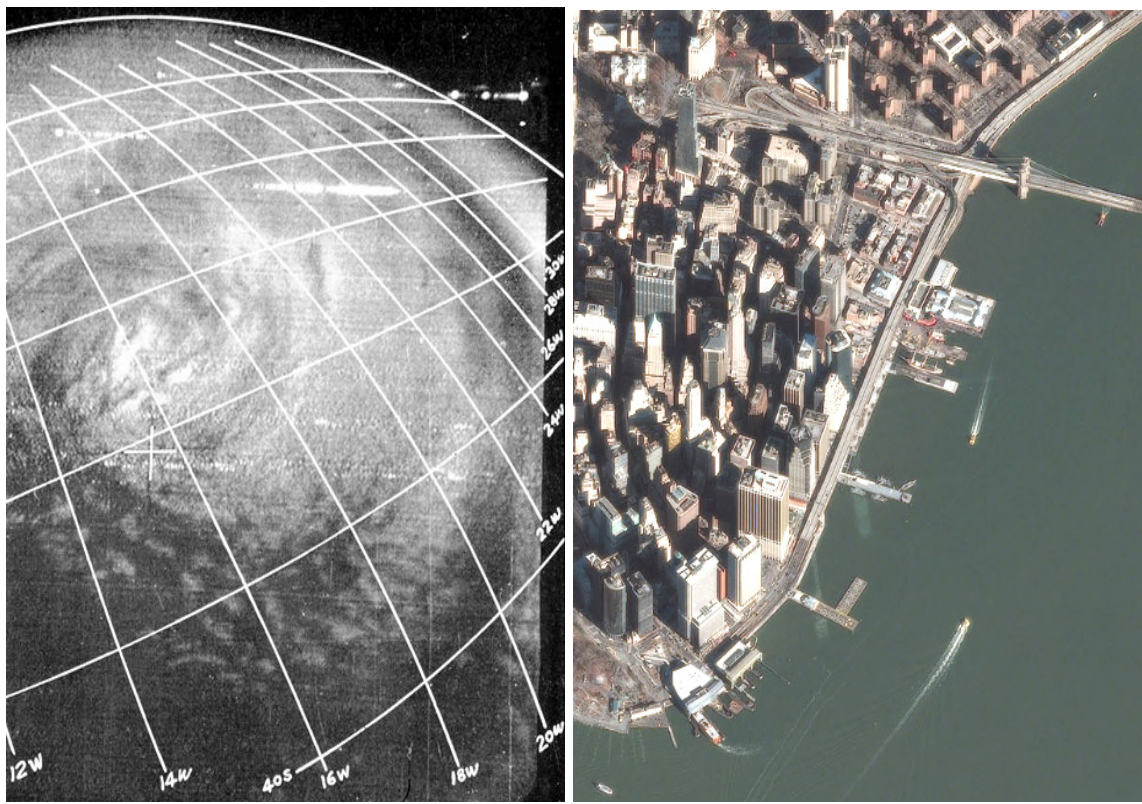

Fonte: NASA, CNES, 2018.

Essa evolução chama dois comentários:

- um progresso considerável na resolução espacial e, portanto, na escala de observação exige cautela quando se trata de destacar uma mudança no meio ambiente ou no clima por um longo período de tempo, uma vez que o olhar do observador mudou durante o mesmo tempo;

- apesar do contraste espetacular entre os desempenhos das décadas de 1960 e 2010, nenhuma revolução tecnológica ocorreu, mas todos os campos técnicos envolvidos (mecânica, ótica, computação) passaram por uma evolução contínua.

A partir do lançamento do primeiro satélite Landsat (1972), a maior quantidade e diversidade de usuários tem trabalhado com imagens de sensores que podemos chamar de "generalistas" que oferecem características interessantes em todas as dimensões. Para ilustrar a evolução das últimas décadas, consideremos dois sistemas espaciais óticos lançados a 30 anos de intervalo: SPOT (fevereiro 1986) et Sentinel-2 (junho 2015). A tabela 1 mostra os desempenhos típicos dessas 
duas gerações de satélites en termos de resoluções espacial, espectral e temporal, assim como os fatores de melhoramento.

Tabela 1: Evolução das caracteristicas de spot a sentinel-2.

\begin{tabular}{|cccc} 
& SPOT & Sentinel-2 & razão \\
\hline resolução espacial & $10 \mathrm{~m}-20 \mathrm{~m}$ & $10 \mathrm{~m}-20 \mathrm{~m}$ & 1 \\
\hline resolução espectral & 4 bandas & 13 bandas & 3,25 \\
resolução temporal & $26 \mathrm{j}$ & 10 dias (1 satélite) & 2,6 \\
\hline
\end{tabular}

Fonte: Elaboração própria.

Os dois satélites tem bandas espectrais de resoluções espaciais diferentes: para SPOT, una banda de $10 \mathrm{~m}$ e 3 bandas de $20 \mathrm{~m}$; para Sentinel-2, 4 bandas de $10 \mathrm{~m}, 6$ bandas de $20 \mathrm{~m}$ e 3 bandas de $60 \mathrm{~m}$ ). O SPOT não tinha a capacidade de observação contínua devido a limitações de armazenamento e de transferência de dados.

É provavelmente a dimensão temporal que oferece a melhoria mais interessante no caso dos satélites Sentinel-2: o período de revisita é de 10 dias e o fato de ter dois satélites opostos na mesma órbita reduz esse período de 10 para 5 cinco dias.

Outros sistemas que favorecem a alta resolução temporal foram recentemente colocados em órbita, em particular:

- O satélite Sentinel-1A possui um radar de abertura sintética que passa a cada 12 dias no equador, e sua alternância com o Sentinel-1B reduz o período para 6 seis dias em muitas regiões. O radar é um sensor chamado all weather ou seja, insensível às condições meteorológicas (as nuvens são transparentes), que aproveita ao máximo à alta resolução temporal, pois cada imagem é explorável.

- O satélite franco-israelense VENuS, lançado em 2017, oferece um período de revisita de dois dias com um ângulo de visada constante, o que deve permitir destacar fenômenos ambientais extremamente dinâmicos, ligados principalmente à fenologia da vegetação. Nesse caso, a melhoria significativa na resolução temporal não ocorreu em detrimento das resoluções espaciais e espectrais, que permanecem comparáveis às do Sentinel-2, mas em detrimento da taxa de cobertura, uma proporção significativa das regiões tropicais sendo inacessível (figura $\mathbf{6 a}$ ). Note-se que essa cobertura é teórica, pois a missão VENuS está programada para observar apenas cerca de 100 locais (figura $6 \boldsymbol{b}$ ) para fins experimentais. 
Figura 6: A missão espacial $\mathrm{VENuS}^{2}$.
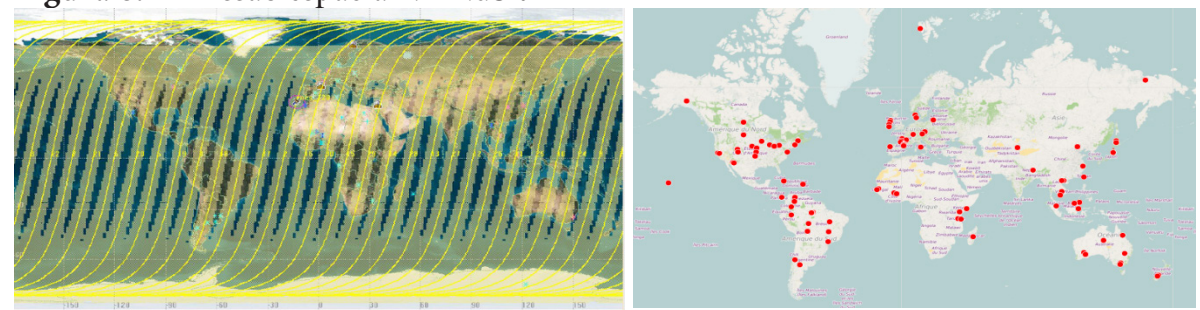

Fonte: NASA, 2018.

\subsection{Desafios tecnológicos da alta resolução temporal}

Sistemas de alta resolução temporal (tipicamente diária) existem há muito tempo sejam de órbita baixa (como NOAA-AVHRR) ou geoestacionária (como GOES), mas têm uma baixa resolução espacial (da ordem do kilômetro, ou um pouco melhor no caso do sensor MODIS por exemplo). Pelo contrário, os sistemas de alta resolução espacial $(1-10 \mathrm{~m})$ costumam ter uma baixa resolução temporal, com possibilidades de aquisição da ordem de três a quatro imagens por ano (dependendo das condições meteorológicas), que não são adequadas para a maioria dos estudos ambientais ou agronômicos.

A alta resolução temporal tem um custo. Para melhorá-la, é preciso abrir mão de outros desempenhos, como a resolução espacial ou espectral. Todas as estratégias que podem ser consideradas para melhorar a resolução temporal têm contrapartidas:

- Aumentando a abertura angular, um ponto da superfície terrestre é visto com uma maior frequência (Figura 7a); porém, é visto com um ângulo de visada variável que pode levar a uma interpretação radiométrica errada (uma vez que a mesma superfície não é vista com a mesma cor se for com perspectivas distintas), variações indesejáveis nas séries temporais ou descontinuidades nas linhas de rejunte em mosaicos; além do mais, o aumento da abertura angular exige uma degradação da resolução espacial.

- Aumentando a agilidade do satélite ou do sensor permite mudar a orientação da visada sob demanda (Figura $7 \boldsymbol{b}$ ), assim que neste caso também, um ponto da superfície terrestre pode ser visto com uma maior frequência (por exemplo, um satélite como Pléiades pode observar um ponto escolhido a cada dois dias, ou até um dia usando dois satélites). Com esta estratégia, o melhoramento da resolução temporal não se faz em detrimento da resolução espacial que pode permanecer alta $(1 \mathrm{~m})$, mas as

\footnotetext{
2 Figura 6a (esquerda): em amarelo, as zonas acessíveis pela missão VENuS

Figura 6b (direita): as áreas observadas pela missão VENuS
} 
imagens sucessivas do mesmo ponto são tomadas com ângulos variáveis, gerando as consequências já mencionadas acima. Outras consequências são os possíveis conflitos de programação quando orientações incompatíveis são pedidas por diferentes usuários, e o fato da aquisição não ser sistemática, assim que em caso de transformação da paisagem (desmatamento, inundação etc.) a existência de uma imagem anterior fica pouco provável.

Figura 7: Estrategias de melhoramento da resolução temporal ${ }^{3}$.
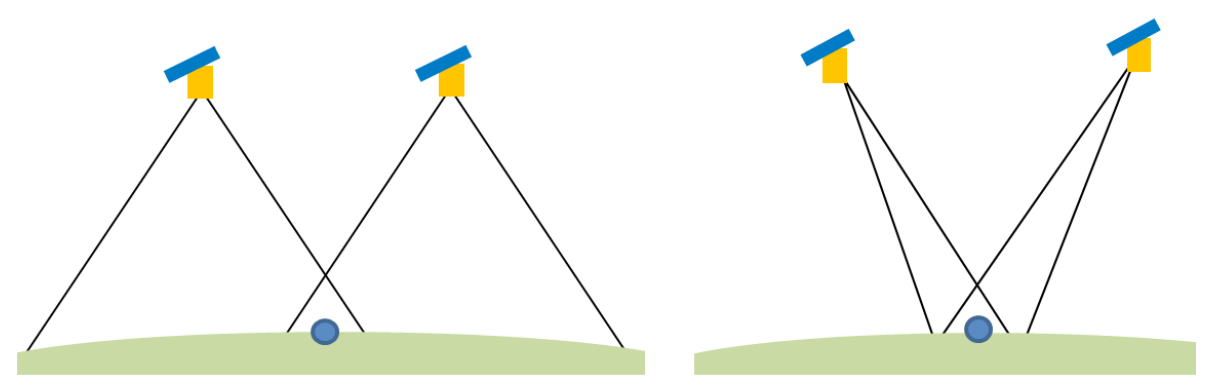

Fonte : Elaborado pelo autor.

Nos dois casos, o número de imagens da mesma área aumenta, mas a qualidade da série temporal pode não ser adequada para a interpretação de mudanças ambientais. Uma solução simples pode ser considerada para evitar essas limitações, mas envolve um custo financeiro maior. Colocando N satélites idênticos sobre órbitas adequadas com a mesma geometria de observação, permite dividir por N o período de revisita do sistema, como os satélites Sentinel-2A e 2B que estão em oposição na mesma órbita heliosincrônica, reduzindo o período de visita de dez a cinco dias (da mesma maneira, o uso dos dois satélites Sentinel$1 \mathrm{~A}$ e $1 \mathrm{~B}$ reduz o período de visita de 12 a seis dias); neste caso, a calibração dos sensores deve ser perfeitamente controlada para que possam ser usados indiferentemente como se fosse o mesmo sensor.

\subsection{Possibilidades oferecidas pela alta resolução temporal}

\subsubsection{Monitoramento de mudanças ambientais}

Sistemas de alta resolução temporal oferecem a possibilidade de acompanhar a evolução da superfície terrestre ao longo do tempo. Essa evolução pode ser de tipo contínuo, periódico ou catastrófico, como visto anteriormente, ou uma combinação dos diferentes tipos. Cada período de revisita (que pode ser de um

Fig. 7a (esquerda): aumento da abertura angular

Fig. 7b (direita): aumento da agilidade (ângulo de visada variável) 
mês, uma semana, um dia por exemplo) dá acesso a alguns fenômenos dinâmicos e pode ser insensível a outros.

Numa série de imagens tomadas em diferentes datas, cada imagem pode indicar mudanças com relação à imagem anterior, assim que a série permite datar uma mudança e pode levar a uma síntese cartográfica na qual cada mudança é apontada e associada a um intervalo de tempo (datas anterior e posterior à mudança).

\subsubsection{Reconhecimento de comportamentos temporais}

Além de descrever a evolução de um fenômeno ambiental ou de escolher a data mais adequada, séries temporais permitem reconhecer um ecossistema ou um cultivo pela sua assinatura temporal. A Figura $\mathbf{8 a}$ mostra a evolução de uma variável ambiental (ou de um índice radiométrico como o NDVI) durante um ano para três cultivos diferentes (exemplo teórico). Aparece uma confusão entre pelo menos dois cultivos nos meses três, cinco e seis, e entre os três cultivos no mês nove, ilustrando o risco de não poder discriminar os diferentes cultivos a partir de uma imagem única, enquanto a disponibilidade de uma série temporal (com uma resolução temporal de um mês nesse exemplo) permite reconstituir o comportamento de cada cultivo ao longo do ano e identificar o mesmo com base nesse critério. A Figura $\mathbf{8} \boldsymbol{b}$ mostra que uma degradação da precisão da medição pode ser compensada pela disponibilidade da série temporal.

Figura 8: Exemplo teórico de variação de uma variável ambiental ${ }^{4}$.
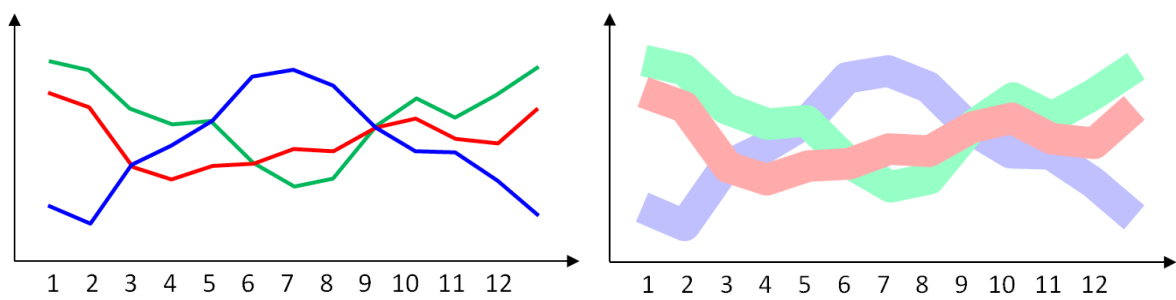

Fonte: Elaborado pelo autor.

Sistemas de alta resolução temporal também tem vantagens práticas até para um análise instantânea sem consideração de mudança.

\subsubsection{Filtragem das nuvens}

No caso das imagens óticas, a superfície terrestre é geralmente escondida por nuvens, e até em estação seca uma taxa de nebulosidade da ordem de 10\%

\footnotetext{
4 Fig. 8a (esquerda): variação de uma variável ambiental (ou de um índice radiométrico como o NDVI) durante um ano para três cultivos (exemplo teórico).

Fig. 8b (direita): mesma variação que fig. 7a com uma precisão radiométrica degradada (exemplo teórico).
} 
impede um estudo ambiental e uma produção cartográfica viáveis. Uma maneira de se livrar das nuvens é através do uso de várias imagens tomadas em diferentes datas, considerando que as nuvens mudam de localização e que para cada pixel, existe pelo menos uma data sem nuvem. Neste caso, é possível produzir uma síntese na qual a nuvem do dia d1 é substituída pelo conteúdo da imagem do dia $\mathrm{d} 2$, onde as datas $\mathrm{d} 1$ e $\mathrm{d} 2$ são escolhidas dentro de uma série temporal (HAGOLLE et al., 2008). O resultado obtido portanto é um mosaico no qual os diferentes pixels são registrados em diferentes datas, como ilustrado pela figura 9 , assim que é preciso supor que as características ambientais não mudaram durante o período de aquisição da série temporal. Esta hipótese pode ser ilusória nos ambientes muito dinâmicos da zona tropical sem a disponibilidade de séries de alta resolução temporal para preservar a qualidade da síntese.

Figura 9: Eliminação de nuvens a partir de uma série temporal ${ }^{5}$.
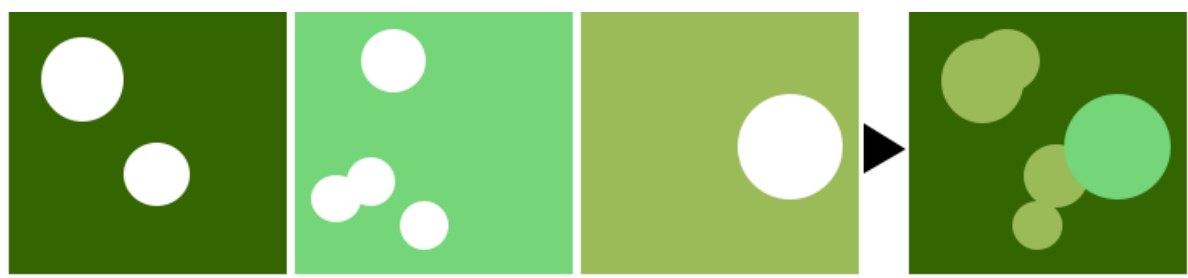

Fonte: Elaborado pelo autor.

O método de eliminação de nuvens descrito acima é apenas um caso particular de uma abordagem mais geral que consiste na combinação de várias imagens tomadas em datas diferentes na mesma área para destacar mudanças rápidas relacionadas com as condições de observação (sensor, luminosidade, atmosfera, geometria de observação) e sem significado ambiental, com o objetivo de separar essas mudanças parasitas e as mudanças da paisagem, e assim melhorar a qualidade da interpretação das imagens. Dois exemplos de tratamentos são comumente implementados com séries de imagens de radar com este objetivo :

- Filtragem multitemporal do speckle. Nas imagens de radar o coeficiente de retroespalhamento relacionado com a umidade, a rugosidade do solo ou a densidade de vegetação, não é diretamente acessível por causa do ruído de speckle que contamina a intensidade do pixel. A maioria dos filtros de speckle consistem em suavizar o ruído substituindo o valor do pixel pela média de uma vizinhança e preservando as feições importantes com critérios estruturais ou estatísticos, mas geram uma degradação da resolução espacial (Lee et al., 1994). Com a disponibilidade de séries temporais de imagens de radar, a

Princípio da eliminação de nuvens a partir de uma série temporal de imagens óticas, mostrando que as variações temporais da paisagem geram uma heterogeneidade espacial na síntese. 
filtragem espacial pode ser substituída por uma filtragem temporal, assim que a imagem pode ser suavizada sem perda da resolução espacial (TROUVÉ et al., 2003). Esta abordagem é mais relevante com uma alta resolução temporal, que torna mais realista a hipótese de uma superfície sem mudança, assim que as variações de intensidade em diferentes datas podem ser atribuídas exclusivamente ao speckle.

- Eliminação dos efeitos atmosféricos em séries interferométricas. A comparação em termos de fase de duas imagens de radar de geometria idêntica pode revelar deformações da superfície (subsidência, deslizamento). Porém, uma variação das condições atmosféricas entre as duas datas (temperatura, pressão, umidade) muda o valor da fase e pode sugerir deformações que não existem (TARAYRE; MASSONNET, 1996). Neste caso também, a disponibilidade de séries temporais, até com precisão variável, permite separar a deformação lenta e coerente da crosta terrestre e as variações rápidas e erráticas da atmosfera. Por exemplo, Ramos (2009) revelou uma deformação tectônica na região de Manaus em séries de imagens de Radarsat apesar de condições atmosféricas muito instáveis.

\subsubsection{Relaxamento das exigências técnicas}

Finalmente, a riqueza da informação temporal disponível em séries de imagens permite compensar a qualidade limitada de cada imagem, e portanto o desempenho limitado do sistema. Os exemplos citados acima mostram que tratamentos específicos aplicados a séries de imagens podem gerar produtos de precisão melhorada. O acesso à informação temporal também oferece um critério adicional de detecção ou identificação, assim que a qualidade de cada imagem pode ser degradada, sendo compensada pelo conhecimento do comportamento temporal dos elementos geográficos estudados. Na Figura 8 acima, temos mostrado que a redução da precisão radiométrica aumenta o risco de confusão entre classes de uso da terra (Figura $8 \boldsymbol{b}$ ), mas pode ser compensada pela disponibilidade da série temporal.

A consequência prática dessa possibilidade é que a qualidade de cada imagem, e portanto as exigências técnicas da concepção do sistema de observação, podem ser menos ambiciosas. Isso reduz a complexidade, o risco de pane e o custo de concepção do sistema.

\section{Aplicações em ambientes tropicais}

\subsection{Considerações gerais}

A disponibilidade cada vez mais importante de séries de imagens de satélite com um período curto de revisita tem oferecido a oportunidade de estudos ambientais no caso de fenômenos muito dinâmicos, sejam de origem natural ou 
antrôpica. Essa possibilidade tem sido favorecida pelo desempenho da última geração de sensores espaciais, cuja calibração geométrica de alta precisão permite uma sobreposição perfeita entre as diferentes imagens, assim que a identificação de pontos de controle e a correção geométrica das imagens não são mais exigidas do usuário como eram até os anos 2000.

O maior desafio deste tipo de análise é a possibilidade de discriminar o fenômeno dinâmico estudado e as outras mudanças que podem ter acontecido no mesmo tempo, sejam elas relacionadas com o meio ambiente ou com as condições de observação (sensor, atmosfera).

O benefício das séries temporais é particularmente importante nas zonas tropicais, onde as mudanças ambientais são mais rápidas, apesar das limitações apresentadas anteriormente. A continuação são apresentados 3 exemplos de análise de séries temporais par estudos de ambientes tropicais. Os fenômenos estudados são tanto naturais (transporte de sedimentos no litoral da Guiana francesa) quanto antrópicos (agricultura no Vietnam, desmatamento da Amazônia).

\subsection{Monitoramento do litoral instável da Guiana francesa}

O litoral da Guiana é muito instável, com uma alternância de fases de sedimentação (permanência de bancos de lama, crescimentos de manguezais, assoreamento de estuários) e de erosão. A complexidade dos fenômenos e as dificuldades de acesso tem incentivado há muito tempo estudos baseados em imagens de sensoriamento remoto para entender o funcionamento dos ecossistemas e ajudar o planejamento da área costeira (POLIDORI, 2008).

Em 2003, a disponibilidade de uma série de 6 imagens de SPOT durante a estação seca (Figura 10) tem permitido demonstrar as possibilidades da alta resolução temporal para estudar a morfologia de um banco de lama. Devido à órbita heliosincrônica do satélite, os instantes de observação são sincronizados com a hora solar local, portanto não são sincronizados com a maré. A consequência é que o banco de lama é visto seis vezes com diferentes alturas de maré, assim que cada imagem gera uma curva de nível desde que o limite entre a lama e a água seja detectado (figura 11). A interpolação dessas curvas dá um modelo digital de elevação da superfície de lama, cujas incertezas são devidas ao contraste limitado entre a lama úmida e a água turva, assim como à hipótese de um banco de lama imóvel durante o período de cinco semanas, uma hipótese discutível porém razoável no caso de uma alta resolução temporal como neste trabalho (GRATIOT et al., 2005). 
Figura 10: Série de 6 imagens do satélite spot mostrando um banco de lama na costa da Guiana francesa em diferentes alturas de maré.

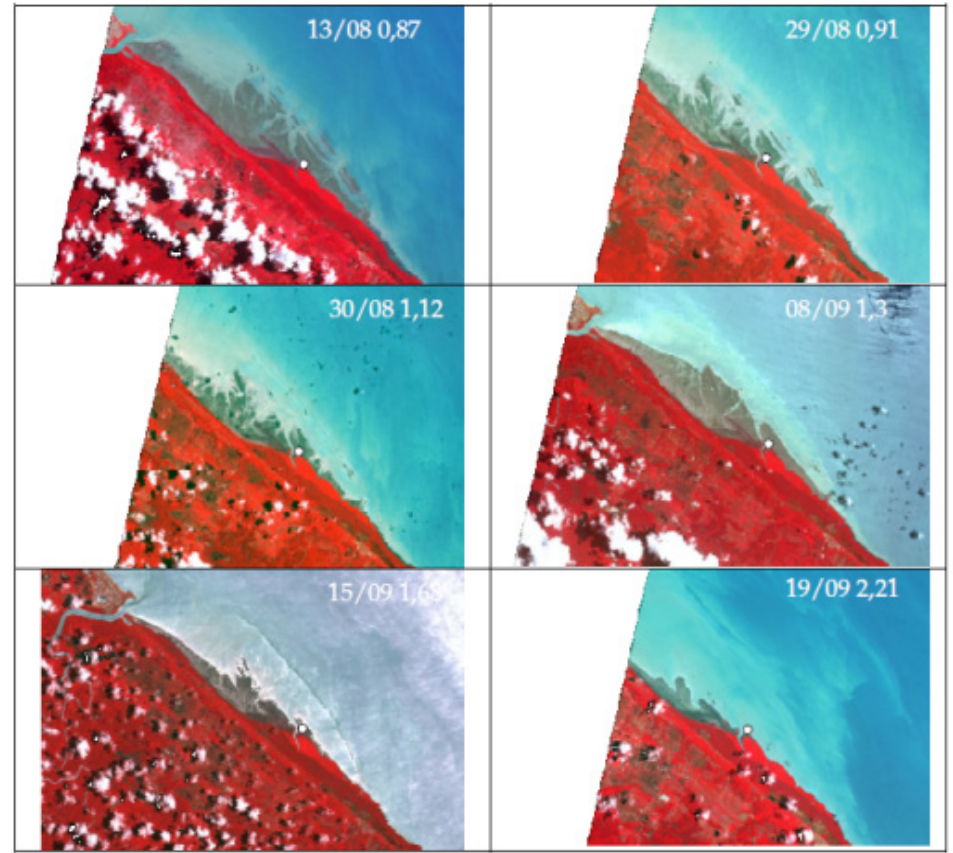

Fonte: GRATIOT et al., (2005).

Figura 11: Curvas de nível obtidas a partir das imagens da figura 9 para a modelagem da superfície do banco de lama.

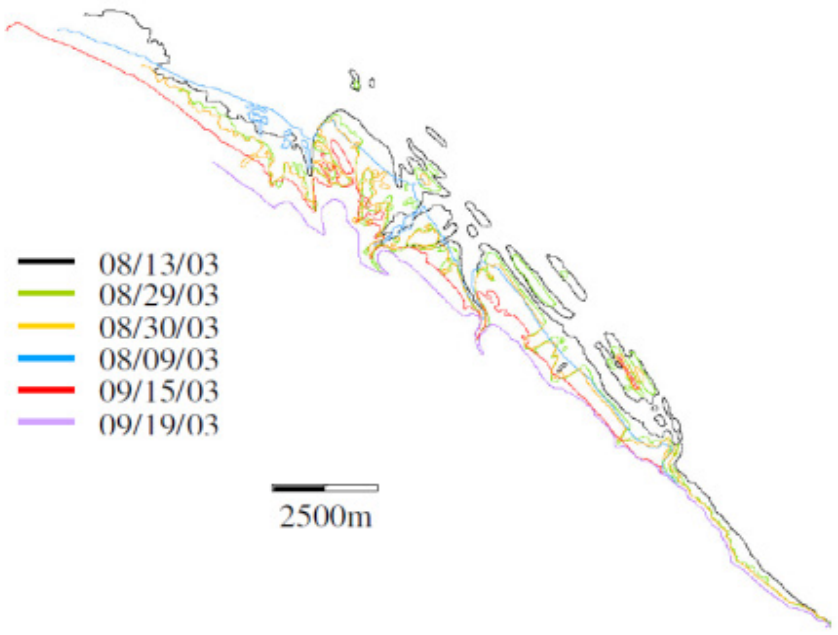

Fonte: GRATIOT et al., (2005). 


\subsection{Monitoramento da produção agrícola no Delta do Mekong}

Séries temporais de imagens de radar tem sido usadas nos últimos anos para monitorar os cultivos de arroz, como no delta do Mekong (BOUVET et al., 2009). O radar é muito sensível à presença de arroz e aos diferentes estados de crescimento do cultivo, principalmente a partir de indicadores como razões entre canais polarimétricos. A figura 12 mostra que a razão $\mathrm{HH} / \mathrm{VV}$ calculada a partir dos dados ASAR do satélite ENVISAT destacam as superfícies de arroz (em comparação com outras superfícies) assim como o ciclo agrícola numa área de três safras, apesar da resolução temporal limitada do sensor (dez imagens por ano).

Figura 12: Evolução da razão media hh/vv calculada a partir de dados asar para classes de pixels «arroz»e «não arroz» e diferença entre as classes numa area agricola do delta do mekong com três safras anuais.

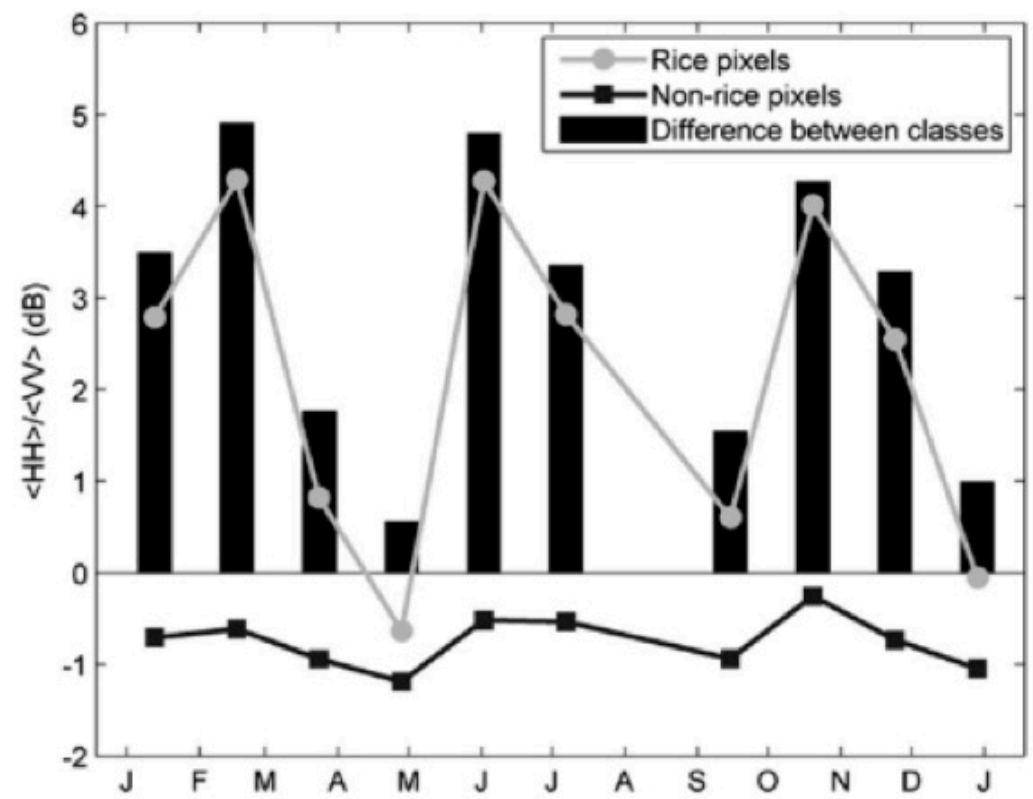

Fonte: BOUVET et al., (2009).

Depois do lançamento dos satélites Sentinel-1, o acesso a mais de trinta imagens por ano tem aumentado muito as possibilidades de monitoramento. Registrando um modelo genérico do crescimento do arroz sobre uma série temporal, é possível monitorar o cultivo particular que está sendo observado, através de características como a data de semeadura (Figura 13a), o estágio fenológico (Figura 13b) ou a altura das plantas (Figura 13c). Trabalhos recentes tem permitido estudar diferentes cenários de produção agrícola e seus impactos, tanto em termos de safra quanto de emissão de metano (HOA PHAN, 2018). 
Figura 13: Cartografia de algumas características do arroz a partir da modelagem da evolução do cultibo e de imagens Sentinel-1: data da semeadura (13a), Estágio fenológico (13b), altura das plantas (13c).
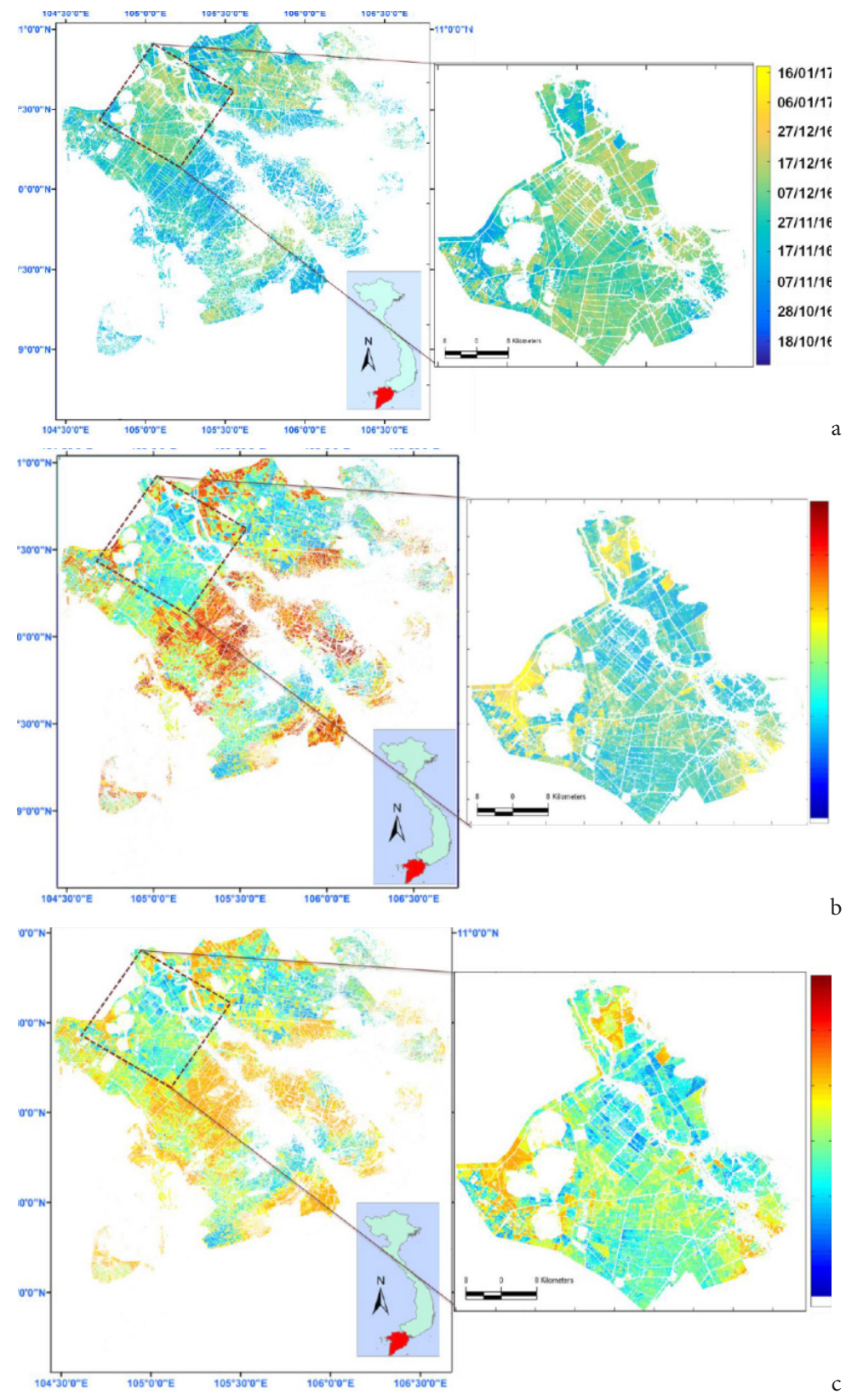

Fonte: HOA PHAN, 2018. 


\subsection{Monitoramento do desmatamento na Amazônia}

O desmatamento das florestas tropicais precisa ser monitorado para poder ser controlado e o uso do sensoriamento remoto é insubstituível, seja para localizar os cortes, medir a sua extensão ou acompanhar a evolução do fenômeno no tempo. Na Amazônia brasileira, o desmatamento tem sido monitorado com diferentes fontes de dados, especialmente as imagens Landsat TM que têm a vantagem de estar disponíveis durante mais de 30 anos. Porém, a cobertura de nuvens que impede as observações durante uma parte do ano incentiva o uso de imagens de radar. Uma característica importante na escolha de um sensor de radar é o comprimento de onda. A banda $\mathrm{C}(\sim 5 \mathrm{~cm})$ interage com a folhagem, enquanto a banda $\mathrm{L}(\sim 25 \mathrm{~cm})$ penetra dentro do dossel e interage com a estrutura das árvores, sendo portanto mais sensível às características da floresta e ao contraste entre a floresta e as áreas de vegetação baixa. A banda $\mathrm{C}$ é menos sensível à degradação da floresta mas é mais disponível e oferece séries de alta resolução temporal. Experimentações com Sentinel-1 mostram que a alta resolução temporal compensa a limitação de sensibilidade das imagens individuais (Le Toan et al., 2017). No exemplo da figura 14, a série de imagens destaca uma área desmatada no período de 17/04/2016 a 03/08/2016. Esse período pode ser reduzido a 12 dias para uma datação mais precisa usando todas as imagens disponíveis. Porém, vale destacar que pode ser difícil detectar o desmatamento se a vegetação cortada não foi retirada ou em caso de chuva. A figura 15 mostra que a diferença floresta / não floresta pode ser imperceptível numa imagem individual e sugere duas abordagens para superar essa limitação :

- identificar a parcela desmatada pela presença da sombra que a floresta intacta projeta sobre a área cortada: essa abordagem é mais adequada para determinar com precisão a data do desmatamento, mas é limitada à margem onde acontece a sombra;

- considerar as variações de intensidade sobre um maior período de tempo para uma interpretação mais segura: aparece claramente a vantagem da série temporal com relação a uma imagem individual (BOUVET et al., 2018). 
Figura 14: Série de imagens sentinel-1 mostrando uma parcela desmatada entre 17 de abril e 3 de agosto 2016 na amazônia brasileira.
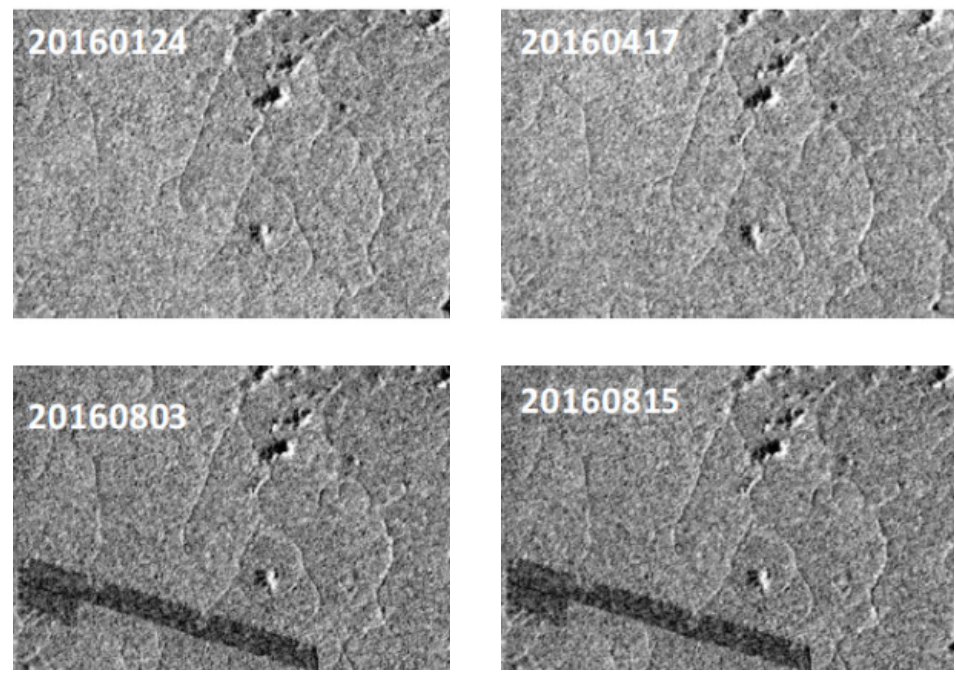

Fonte: LE TOAN et al., (2017).

Figura 15: Evolução de um índice radiométrico calculado a partir de série de imagens sentinel-1 em 3 áreas: floresta (verde), área desmatada (preto), sombra na margem do corte (vermelho), na amazônia peruana.

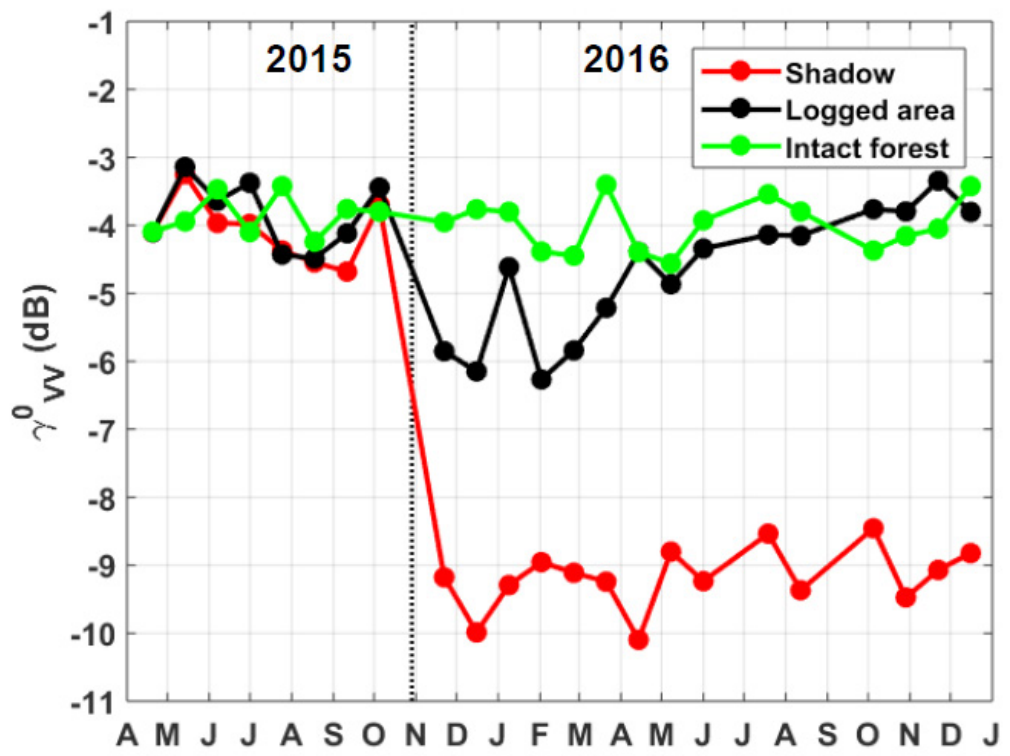

Fonte: BOUVET et al., (2018). 


\section{Conclusão}

A disponibilidade de séries de imagens de satélite com alta resolução temporal tem oferecido novas possibilidades, tanto para tornar mais segura a interpretação das imagens quanto para poder acompanhar as evoluções dinâmicas do meio ambiente. As possibilidades e as limitações da alta resolução temporal têm sido apresentadas, discutidas e ilustradas com trabalhos cujos autores aproveitaram a riqueza da informação temporal para monitorar fenômenos dinâmicos, tanto naturais quanto antrópicos. Os exemplos escolhidos são estudos desenvolvidos em áreas tropicais, onde as mudanças do meio ambiente são mais dinâmicas e onde, portanto, a alta resolução temporal traz o maior benefício. 


\section{Referências}

BOUVET A., LE TOAN T., LAM-DAO N. (2009) Monitoring of the Rice Cropping System in the Mekong Delta Using ENVISAT/ASAR Dual Polarization Data. IEEE Transactions on Geoscience and Remote Sensing, v. 47, n. 2, p. 517-526. DOI: 10.1109/ TGRS.2008.2007963

GRATIOT N., GARDEL A., POLIDORI L. Remote sensing based bathymetry of the highly dinamic amazonian coast, International Coastal Symposium, Hornafjörður, Islande, 5-8 jun, 2005 (CD-ROM).

HAGOLlE O., HUC M., VILLA PASCUAL D., DEDIEU G. (2008) A multi-temporal method for cloud detection, applied to FORMOSAT-2, VEN $\mu$ S, LANDSAT and SENTINEL-2 images. Remote Sensing of Environment, v. 114, n. 8, 2008, p. 1747-1755.

HOA PHAN. Suivi des surfaces rizicoles par télédétection radar, tese de doutorado, Université de Toulouse, 2018.

LEE J.S., JURKEVICH I., DEWAELE P., WAMBACQ P., OOSTERLINK A. (1994) Speckle filtering of synthetic aperture radar images: a review. Remote Sensing Reviews, v. 8, p. 313-340.

LE TOAN T., MERMOZ S., BOUVET A., VILLARD L.; POLIDORI L. Monitoring of tropical forests using SAR data - Application to the Amazon region. $18^{\circ}$ Simpósio Brasileiro de Sensoriamento Remoto, Santos. Anais INPE, 2017. p. 8076-8083.

POLIDORI L. (2008) Remote sensing and coastal ecosystem monitoring in French Guiana : research and achievements over a decade. International Archives of the Photogrammetry, Remote Sensing and Spatial Information Sciences. v. 37, Part B8. Beijing, p. 627-631.

TROUVÉ E., CHAMBENOIT Y., CLASSEAU N., BOLON P. Statistical and operational performance assessment of multitemporal SAR image filtering. IEEE Trans. Geosci. Remote Sens. v. 41, p. 2519-2530, 2003.

TARAYRE H., MASSONNET D. Atmospheric propagation heterogeneities revealed by ERS-1. Geophys. Res. Lett. 23, p. 989-992, 1996.

RAMOS F. L., LAUDAU L., MIRANDA F. P., SILVA C. L. Use of Information Derived from Radar Remote Sensing (RADARSAT-1) Interferometry and SRTM MOSAIC) for Mapping Neotectonic Activities in the REgion of Manaus City (Amazonas State). Proc. 'Fringe 2009 Workshop', Frascati, Italy, 30 Nov. - 4 Dec. 2009 (ESA SP-677, March 2010), 2009. 